\title{
Organizational and Financial Aspects of Enterprise Sustainable Development
}

\author{
Gaukhar Kodasheva ${ }^{1}$, Asel Kayipkulova ${ }^{2}$, Nadezhda Piontkevich ${ }^{3, *}$, Ekaterina
}

Shatkovskaya ${ }^{4}$

\author{
${ }^{1}$ Eurasian National University named after L. N. Gumilyov, Astana, Republic of Kazakhstan 4 \\ ${ }^{2}$ Osh Technological University named after ac. MM. Adyshev, Osh, Kyrgyzstan \\ ${ }^{3}$ Ural State University of Economics, Yekaterinburg, Russia \\ ${ }^{4}$ Ural State Mining University, Yekaterinburg, Russia \\ ${ }^{*}$ Corresponding author.Email: nspiont@gmail.com
}

\begin{abstract}
Currently, enterprises operate under the influence of numerous and varied factors of the external and internal environment. Enterprises are forced to react to these influences and take them into account in the planning process and further implementation of their activities. Ensuring sustainable development of enterprises is an important strategic task of in-house management, which is solved through increasing the competitiveness and investment attractiveness of a business. The purpose of the article is to develop theoretical and methodological aspects of managing the in-house activities of an enterprise and, on this basis, to offer practical recommendations for improving the management of functional areas of its activity to ensure sustainable development of the enterprise. The article uses a complex of modern methods for collecting, processing and interpreting the initial information. The author's organizational and financial model of in-house management of the enterprise is proposed and the organizational and financial aspects of management of various functional areas of economic activity are investigated.
\end{abstract}

Keywords: sustainable development of enterprises, in-house management, marketing management, $R \& D$ management, production management, logistics management, personnel management, financial management.

\section{INTRODUCTION}

The modern market economy is based on such basic actors as households, organizations of all forms of ownership, and the state as a collective entrepreneur. At the same time, organizations, including associations of organizations, are the main economic entity that forms the national gross domestic product; therefore, the successful and stable functioning of the entire national economy depends on their sustainable development of an enterprise. In these conditions, the problems of internal management of enterprises acquire special relevance. The purpose of in-house management the authors see in increasing the efficiency of management of the business functional areas of activity at all levels of management. For this, the authors have developed a financial and economic model of internal management, which includes, on the one hand, the hierarchy of enterprise management levels, and, on the other hand, the management systems of the enterprise by functional areas of activity within these hierarchical levels (that is, how to plan and implement the economic policy of the enterprise at the strategic and operational levels) with taking the financial management system as the basic one.

\section{MATERIALS AND METHODS}

The article uses a set of basic research methods, namely: method of scientific abstraction, logical method, dialectical method, expert assessment method.

The methodological basis of the organizational and financial aspects of sustainable development of enterprises, according to the authors, are various levels of management at the enterprise, comprising special organizational, economic and financial instruments: 
- economic policy, including: marketing policy, R\&D policy, production policy, logistics policy, personnel policy and financial policy;

- enterprise strategies, including: corporate strategies, business strategies, functional strategies;

- operational management of the enterprise by functional areas of activity.

\section{RESULTS AND DISCUSSION}

The organizational and financial model of in-house management proposed by the authors includes a system of regulation of internal management at the level of developing an enterprise's economic policy and its implementation at the strategic and operational levels (Figure 1).

To ensure sustainable development of the enterprise, it is necessary to monitor the implementation of a multilevel model of in-house management in the functional areas of the enterprise [9-13]. Let us consider some organizational and financial aspects of control procedures in various functional areas of economic activity.

\subsection{Management of Marketing}

Management of marketing as a functional area of the organization provides for the effective implementation of marketing policies, including price, sales, communication policies [1]

To achieve the set goals of the marketing policy, it is necessary to implement the following activities:
- at the stage of planning sales, it is necessary to foresee the participation of not only commercial, but also financial, planning and economic, as well as production services, which will allow an objective assessment of the market potential, taking into account information on the cost of sales and production capabilities, and will also eliminate deliberate underestimation of the forecast volumes of realization;

- financial and economic services, heads of sales and marketing departments should be involved in the pricing process; price coordination by the financial service should be carried out taking into account information about the cost of production and the required marginal profit;

- to determine the conditions for the provision of discounts;

- granting deferred payments is a prerequisite for implementing a strategy to expand market share, however, uncontrolled granting deferrals can lead to an increase in overdue receivables and a decrease in the quality of financial indicators;

- provided that the organization grants a deferred payment on an ongoing basis, it is necessary to fix the procedure for managing account receivables and appoint a person (department) responsible for the current monitoring of the level of account receivables and coordination of measures to collect them;

- control of the client base and information about marketing plans provides for the introduction of IT control that restricts the sales manager's access to data on

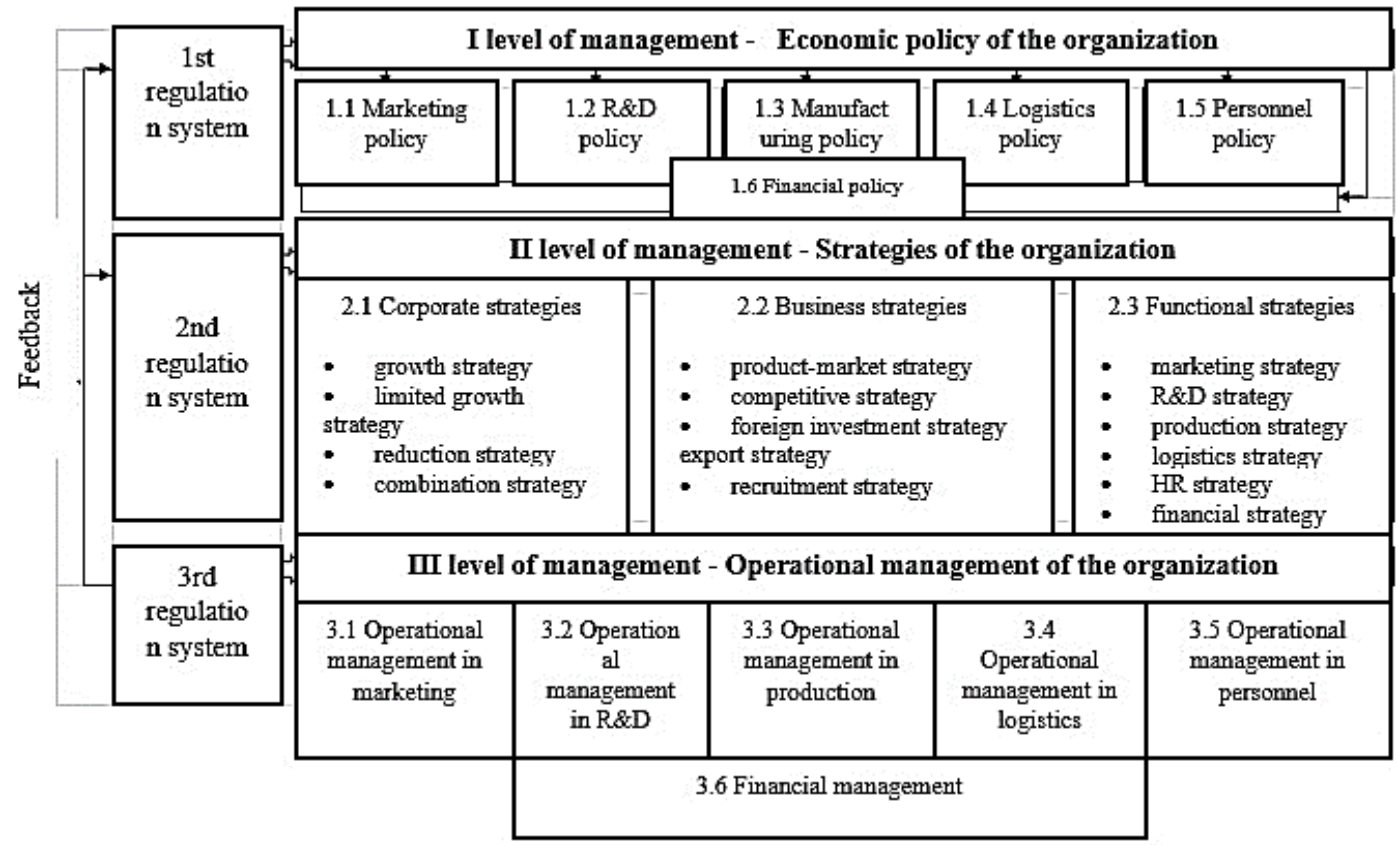

Figure 1 Organizational and financial model of internal management of an enterprise 
those counterparties that he does not supervise, and the ability to copy information in any way;

- avoiding the loss of customers is possible by regularly monitoring the implementation of orders and conducting a random check of already completed orders;

- evaluation of the effectiveness of marketing costs based on a detailed sales plan;

- ensuring a competitive selection of counterparties in the process of marketing activities implies the creation of a tender committee, which includes employees of other divisions of the organization who are not formally interested in the results of tenders (e.g. financial service, economic security division); as an additional control procedure, checking the affiliation of counterparties and employees of the marketing department is to be used;

- delineation of areas of responsibility between employees of the marketing department;

- the use of key performance indicators (KPI) for the marketing department and its employees in order to improve the efficiency of the organization's sales activities; the KPI data is based on the marginal profit from the sale transaction and the status of the level of receivables;

- implementation of verification of the effectiveness of control procedures to increase the profitability of sales and the timeliness of order execution.

Integrated marketing management is associated with control over the implementation of pricing, sales and communication policies, which is aimed at ensuring an increase in the volume of sales of the organization's products, subject to a simultaneous increase in marginal income for products and a decrease in overdue receivables

\section{2. $R \& D$ Management}

$R \& D$ Management within the framework of innovation is carried out in order to create a new or improved product sold in the market, as well as a new or improved technological process used in practice [6].

Increasing the efficiency of the use of scientific developments and the introduction of the results of fundamental and applied research into production when pursuing an innovation policy is aimed at updating the production potential of organizations, increasing the competitiveness of the organization and its products, as well as increasing the profitability of R\&D.

\subsection{Production Management}

Production Management is the main functional area of activity of any non-financial organization, it is a system of economic relations regarding the management of production resources, management of production flows and improving the quality of products (work performed, services provided).

The resource provision policy determines the procedure for the acquisition of goods and services, the rules for the delivery and storage of raw materials and finished products in the warehouse. To reduce losses and prevent fraud on the part of employees in this area, it is necessary to monitor the quality of implementation of this policy.

Monitoring the risks associated with procurement activities and applying ways to mitigate them:

- the risks of disruption of supplies can lead to penalties, and, in the event of a production interruption, to huge losses. The resource provision policy should establish procedures to ensure that the deadlines for receiving goods and services are met;

- risk of warehouse overstocking can manifest itself in the form of serious cash gaps. The regulations should provide for the delivery time and frequency taking into account the real needs of the organization;

- the risks of employee malpractice should be identified by the organization's security service, however, the regulation should contain rules and control procedures to reduce such risks (e.g., centralization of purchases or the introduction of special performance targets (KPI) for managers depending on the level of costs for purchased products). Decisions on the choice of a counterparty and on the terms of cooperation with him should be made collectively. In addition, it is necessary to delineate powers and responsibilities between departments and employees involved in the process.

Determining the procedure for selecting suppliers provides for a decision-making algorithm that depends on the total amount of the contract; accordingly, the resource provision policy should provide for several procedures for selecting suppliers (for example, basic and simplified) with an indication of the criteria for their application. Next, the number of suppliers must be determined.

Determination of the order of procurement planning. The CFO is to make sure that the figures stated in the procurement budget do not conflict with the production plan and the sales budget [2]. The resource provision policy should contain a condition according to which the decision to purchase goods and services is made on the basis of applications prepared by specialists of the planning and economic and production (or sales department) divisions of the organization, broken down into convenient delivery periods.

\subsection{Logistics Management}

Logistics Management is the management of storage and transportation of material resources outside and inside the organization. 
The control of the logistics system should be carried out both by large organizations with their own logistics departments, and by organizations of medium and small businesses that use outsourcing of transport services. The authors propose to implement the following list of measures to control logistics in the organization:

- to create a logistics department and regulate its activities. In organizations, in most cases, the main logistics functions (purchasing, delivery, warehousing, etc.) are distributed between several services: purchasing, sales, warehouse and production facilities, while there is no single unit responsible for the entire logistics process. This is justified provided that the costs of organizing this process are low, otherwise it is more expedient to create a specialized structural unit and make it responsible for the overall coordination of logistics [4]. In order to ensure the efficient functioning of the logistics service, it is necessary to establish key performance indicators for it that correspond to the strategic goals of the organization (for example, the level of logistics service; the growth rate of the turnover of warehouse stocks; warehousing costs; the unit cost of transportation of one unit of products; the share of illiquid commodity items in the structure of stocks and etc.);

- switch to a competitive selection of transport service providers. This measure will help mitigate the risks of unjustified overstatement of the cost of services of logistics operators. To improve the quality of planning logistics costs, this department must be introduced into the budgeting process. The following will help to increase the transparency of the selection of contractors: clear terms of the tender documentation and independent examination of the most expensive items costs; the inclusion of representatives of related departments, including the financial service and the department of economic security, in the procurement commissions; conducting random checks of the affiliation of the employees with transport organizations;

- it is possible to optimize the costs of logistics processes by including special criteria in the contract with the carrier, the fulfillment of which on the part of the organization will become a condition for reducing the cost of transport services, namely: planning supplies and shipments and the advance transfer of this information to the counterparty, which will help reduce the peak loads of the latter, by allowing the contractor to reduce the number of redundant staff and capacity [8]; consolidation of applications from the organization in order to ensure the full load of the contractor's transport; unification of cargo packaging in order to optimize its placement in vehicles and warehouse premises of the contractor, as well as the use of bar codes that speed up its processing. The organization will be able to reduce logistics costs by redistributing the logistics service in favour of the most profitable commodity items identified by the results of the $\mathrm{ABC}$ analysis [7];

- to ensure control over capital logistics expenditures, including the costs of purchasing (building) objects of its own logistics complex, as well as creating a distribution centre or a subsidiary transport organization. At the stage of planning capital expenditures, a transparent selection and high-quality study of the investment project should be ensured, covering the assessment of its feasibility; checking for correctness of calculations, validity of proposals; preparation of a schedule for the implementation of major activities; formation of a project management scheme and its risks. In the process of implementing capital expenditures on logistics, it is necessary to monitor compliance with the schedule of planned activities, as well as the expenditure of funds intended for the implementation of this project;

- optimization of logistics processes and workflow with counterparties should be done at the stage of

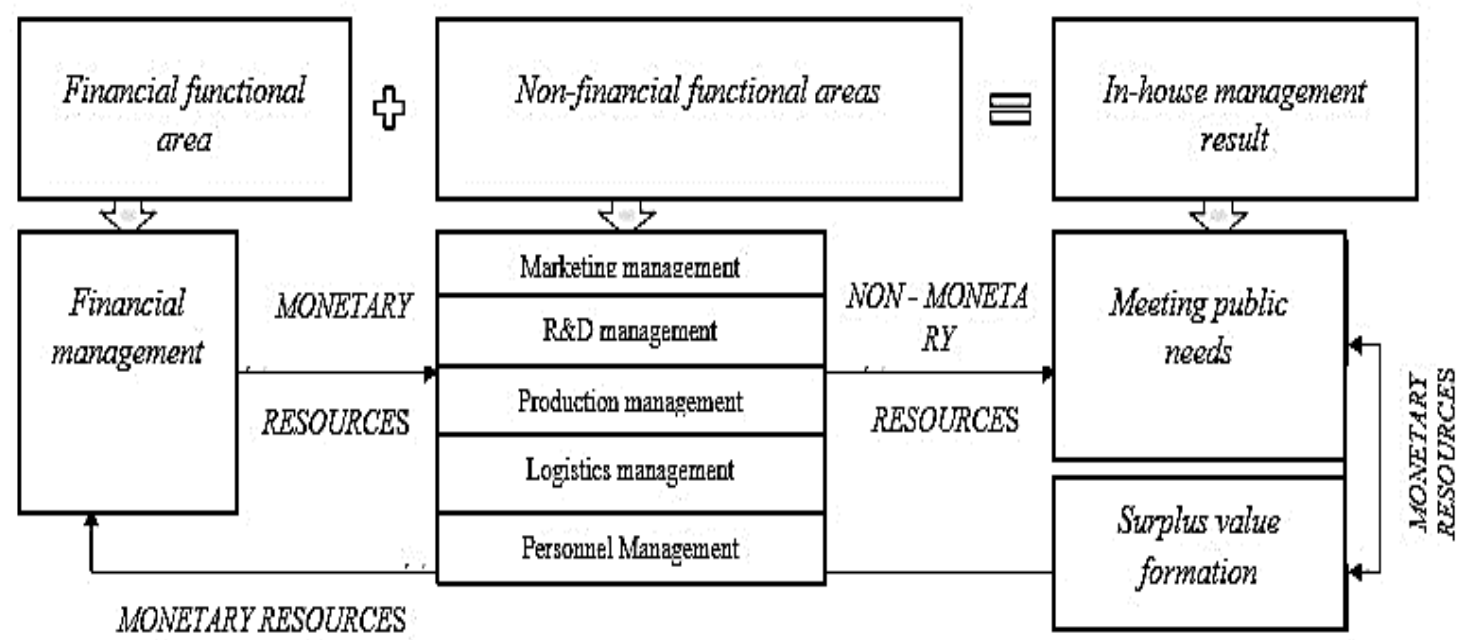

Figure 2 The role of financial management in the system of in-house management of an enterprise 
planning contractual relations with a freight forwarding organization. When concluding a contract on a long-term basis, it is necessary to stipulate the following conditions in it: provision of transport for loading; acceptance of the cargo for transportation and its release to the consignee; calculations (their form and order). In the course of the contractual relationship, it is necessary to selectively track the primary documents of the logistics process (waybills) and check the presence of essential data in them (for example, about the type, name, quantity, weight of the cargo and the timing of its delivery; about the vehicle, the procedure for its provision and use; about the point of departure and points of destination of transportation; on the conditions of delivery and its cost; on the declared value (value) of the cargo, as well as the presence of the signature of the authorized representatives of the organization and the carrier organization);

- it is necessary to establish control over the work of the warehouse to reduce the risk of theft and shortages in the warehouse, while it is necessary to ensure regular control of the movement of stocks, receipts and write-offs. Carrying out a regular inventory of the warehouse will make it possible to prevent malpractice of warehouse employees;

- to introduce special technical means in the logistics process (for example, video surveillance systems installed at the points of product shipment and order picking). This measure will help reduce the risks of malpractice and theft in the logistics department. Monitoring the movement of cargo in real time, tightening of the access regime in office premises, establishing systems that record the time of arrival and departure of employees, the introduction of selective examination of employees leaving the workplace at the end of the working day will reduce the risk of losses (shortfalls, unreasonable write-offs of spoiled or damaged goods).

The implementation of the measures proposed by the authors will reduce the cost of transporting raw materials, materials and finished products, their storage and movement within the organization.

\subsection{Personnel Management}

Personnel Management as an independent functional area of activity is proposed to be considered in the following areas:

- increasing the loyalty of employees to the management of the organization through the introduction and use of a motivation system;

- minimization of risks associated with the human factor - arising as a result of unsatisfactory organization of the business's management process, insufficient personnel training, managers exceeding official powers and other violations.
In order to increase loyalty, it is necessary to motivate heads of departments, their deputies, as well as employees responsible for key functions of business processes. Correctly selected Key Performance Indicators (KPIs) will help motivate these professionals to perform effectively in control procedures. General performance indicators of financial control performance should be linked to the amount of bonuses for all business process owners, which will motivate employees to correctly perform standard control functions: regular monitoring of the effectiveness of control procedures, which is necessary to gain confidence in achieving the required result, and timely implementation of corrective actions. This function is needed to eliminate violations identified with the help of independent audits.

Special indicators will help to motivate employees responsible for financial control in different structural divisions and business processes, which indirectly affect the increase in the effectiveness of control functions both in the organization as a whole and in certain areas of its activities [5].

Well-coordinated work of organizational units (risk management, HR, PR and IT services, as well as the internal audit unit, security service and legal department) will help counteract fraud effectively [3].

\subsection{Financial Management}

Financial Management as an independent functional area of the organization's activities occupies a special place in the system of in-house management. The financial functional area of activity is the supplier of monetary resources to ensure the functioning of the organization, including all non-financial functional areas of activity (Figure 2).

The non-monetary result of in-house management in the context of production management and related nonfinancial functional areas is the production of products, the performance of work and the provision of services. The monetary result of all functional areas of activity is the formation of surplus value. At the same time, the totality of non-monetary and monetary results of in-house management of the organization's activities makes it possible to ensure the satisfaction of social needs.

\section{CONCLUSION}

The in-house management of an enterprise, according to the authors, is a system of economic relations regarding the management of all functional areas of activity with the allocation of finance as an economic basis in the management system for marketing, R\&D, production, logistics and personnel, which ensures the organization of a balanced circulation of monetary and, on this basis, non-monetary resources in order to 
implement the economic policy of the owners of the organization.

The purpose of the enterprise's internal management is to form an effective management system for internal business processes to achieve the goals of the enterprise, including ensuring sustainable development through maintaining the status of a permanent organization, ensuring the competitiveness of the enterprise and its products and improving the quality of interaction between the subjects of the macro- and microenvironment.

The key to ensuring sustainable development of an enterprise is the formation of surplus value in the process of using financial and non-financial resources as a source of meeting the interests of external and internal stakeholders.

\section{REFERENCES}

[1] A.M. Karminsky, Controlling in business. Methodological and practical bases for constructing controlling in organizations. Finance and statistics, 1998, p. 256.

[2] A.M. Karminsky, S.G. Falko, A.A. Zhevaga, N.Yu. Ivanova, Controlling: textbook. Finance and statistics, 2006, p. 336.

[3] Controlling concept: Management accounting. Reporting system. Budgeting. Horvath \& Partners; Per. with him. Alpina Business Books, 2005, p. 269.

[4] Sergeeva, Corporate logistics. 300 answers to the questions of professionals. Under total. and scientific. INFRA-M, 2004, p. 976.

[5] J. D. Martin, VBM - Value Based Management: The Corporate Response to the Shareholder Revolution. Per. from English under scientific. Balance Business Books, 2006, p. 272.

[6] "On the Concept of Innovation Policy of the Russian Federation for 1998-2000". Decree of the Government of the Russian Federation N 832 of July 24, 1998. http://www.consultant.ru/cons/cgi/o nline. cgi? req $=$ doc $\&$ base $=E X P \& n=258811 \# 018580$ 159624444303.

[7] H.Y. Folmuth, Controlling Tools. Publishing house "Omega-l", 2007, p. 127.

[8] H.Y. Folmuth, Controlling tools from A to Z. Finance and statistics, 1998, p. 288.

[9] R. Otero, Angel. An information security control assessment methodology fororganizations' financial information. International Journal of Accounting Information Systems 18 (2015) pp. 26-45. DOI: http://dx.doi.org/10.1016/j.accinf.2015.06.001.
[10] V.F. Grankin, Innovative approach to formation of financial characteristics of reference development dynamics of enterprise. Messenger of The Kursk state agricultural academy 4 (2017) pp. 66-72.

[11] M.J. Flannerya, K.W. Hankins, Estimating dynamic panel models in corporate finance. Journal of Corporate Finance 19 (2013) pp. 1-19. DOI: http://dx.doi.org/10.1016/j.jcorpfin.2012.09.004.

[12] P. Benczur, St. Karagiannis, V. Kvedaras, Finance and economic growth: financing structure and nonlinear impact. Journal of Macroeconomics 2018. DOI: https://doi.org/10.1016/j.jmacro.2018.08.001.

[13] Li Shengfeng, Hoque Hafiz, Thijssen Jacco, Firm financial behavior dynamics and interactions: A structural vector autoregression approach. Journal of Corporate Finance 69 (2021) p. 102028. DOI: https://doi.org/10.1016/j.jcorpfin.2021.102028. 